\title{
REVIEW
}

\section{Emerging Therapies for Inflammatory Bowel Disease}

\author{
Roni Weisshof $\cdot$ Katia El Jurdi · Nada Zmeter · David T. Rubin
}

Received: August 15, 2018 / Published online: October 29, 2018

(C) The Author(s) 2018

\begin{abstract}
Inflammatory bowel disease (IBD) is a chronic heterogeneous group of diseases that has undergone major advances in the understanding of its etiology and pathogenesis in recent years. The development of biologics had resulted in better overall management of the disease, including lower rates of surgery and better longterm clinical and patient-reported outcomes. Treatment modalities have either been newly developed or extrapolated from their approved use for a different indication. Modes of action and treatment targets have varied as well. Treatments such as vedolizumab and ustekinumab, as well as second-generation corticosteroids have been approved by the US Food and Drug Administration (FDA) for the treatment of IBD. Other agents are currently being developed at various stages of clinical trials including antiadhesion agents such as etrolizumab and abrilumab, JAK inhibitors such as tofacitinib, and anti-trafficking molecules. Toll-like receptors and phosphatidylcholine are also new
\end{abstract}

Enhanced digital features To view enhanced digital features for this article go to https://doi.org/10.6084/ m9.figshare.7083086.

R. Weisshof $\cdot$ K. El Jurdi $\cdot$ N. Zmeter .

D. T. Rubin $(\bowtie)$

Inflammatory Bowel Disease Center, University of

Chicago Medicine, Chicago, IL, USA

e-mail: drubin@uchicago.edu promising emerging targets that are being investigated in phase 3 clinical trials. It is projected that many therapies will become available in the coming years if supported by the results of current clinical trials. This will provide IBD patients with a wide array of options and allow physicians to choose the best therapies for each individual patient.

Keywords: Crohn's disease; Inflammatory bowel disease; Therapy; Ulcerative colitis

\section{INTRODUCTION}

The past two decades have been characterized by vast progress in our understanding of the etiology and pathogenesis of inflammatory bowel disease (IBD). The exact etiopathogenesis of IBD remains unknown, but multiple inflammatory pathways and cellular and microbiota contributions have been identified, with subsequent development of novel treatments that exploit these different observations (Fig. 1) [1].The landmark studies regarding the effectiveness of anti-tumor necrosis factor- $\alpha$ (antiTNF) have improved our ability to offer significant and longstanding remission to patients and even influence disease course [2]. Nevertheless, approximately $30 \%$ of patients are primarily unresponsive to anti-TNF and about onethird eventually lose response to the drug, 


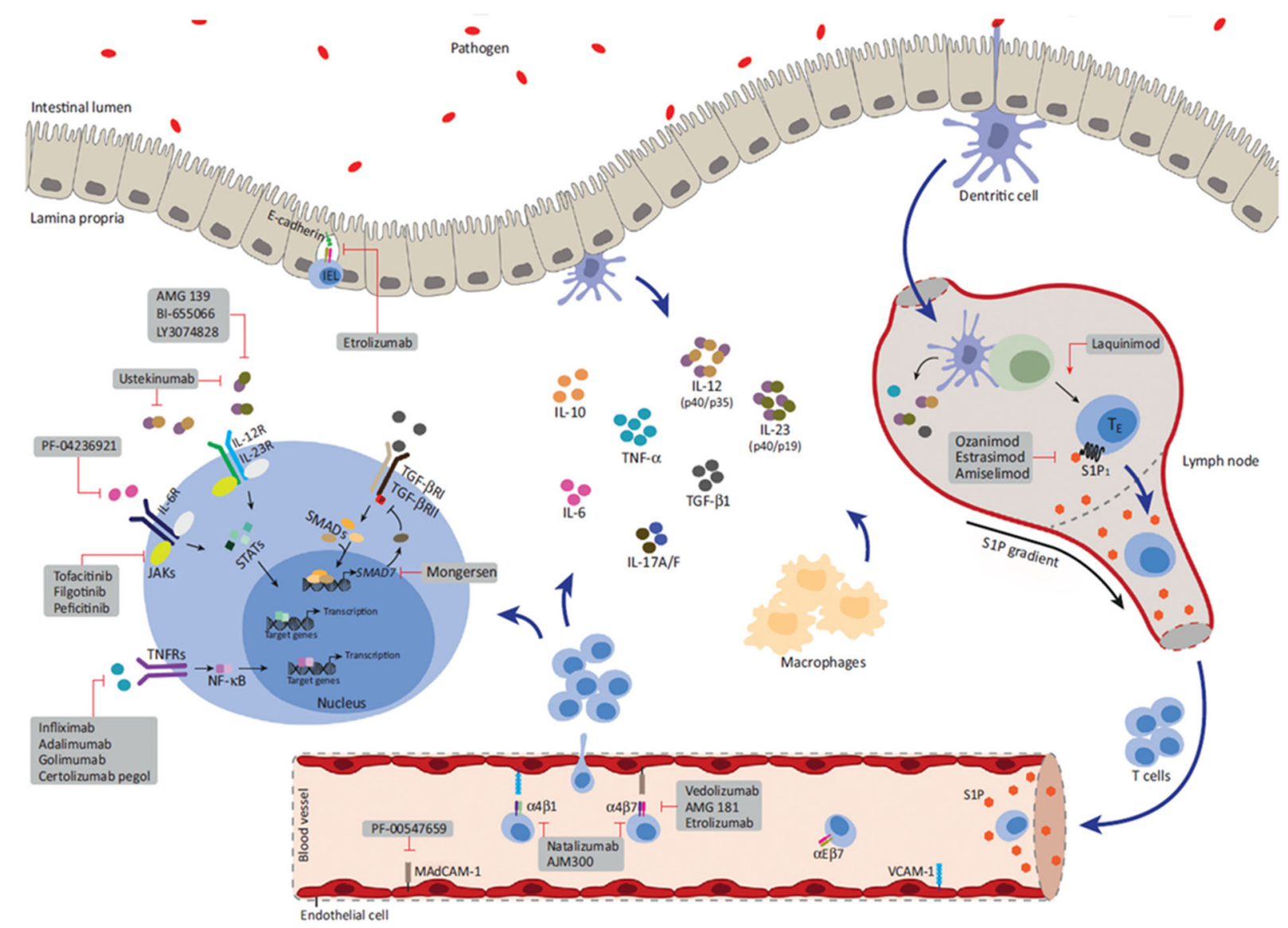

Fig. 1 Proposed pathways and signaling molecules involved in the pathogenesis of IBD, including new developing therapies that target them. IEL intraepithelial lymphocyte, IL interleukin, JAK Janus kinase, MAdCAM mucosal addressin cell adhesion molecule, NF- $\mathrm{KB}$ nuclear factor- $\mathrm{\kappa B}$, $\mathrm{P}$ phosphorylation, S1P sphingosine-1-phosphate, S1P1 S1P receptor 1, STAT signal transducer and activator of

mostly in the first year of treatment [3]. Thus, the need arises for other more efficient and safer therapeutic options. This review highlights some of the recently approved and upcoming therapeutic options that promise better management of IBD. This article is based on previously conducted studies and does not directly contain any studies with human participants or animals performed by any of the authors.

\section{NEW ANTI-TNF AGENTS}

AVX-470 is an orally administered polyclonal anti-TNF antibody isolated from the colostrum transcription, TE effector T cell, TGF- $\beta$ transforming growth factor- $\beta$, TGF- $\beta$ R TGF- $\beta$ receptor, TN naïve T cell, TNF- $\alpha$ tumor necrosis factor- $\alpha$, TNFR TNF receptor, VCAM vascular cell adhesion molecule. Modified with permission from Coskun. M, Vermeire. S \& Nielsen O.H. Novel Targeted Therapies for Inflammatory Bowel Disease. Trends Pharmacol Sci. 2017; 38: 127-142. [1]

of cows immunized with TNF. Theoretically, the drug neutralizes TNF locally in the gastrointestinal tract, minimizing systemic exposure. The purified antibodies are formulated in delayed-release enteric-coated capsules releasing at $\mathrm{pH} 6.0$ in the small intestine and colon following oral administration. These are large molecules (molecular weight $\sim 160-900 \mathrm{kDa}$ ) that are poorly absorbed into the systemic circulation. Recently, two preliminary studies have demonstrated the safety, pharmacokinetic changes, and clinical efficiency of the drug in moderate-to-severe active ulcerative colitis (UC) $[4,5]$. One-third of the patients were anti-TNFexperienced. A larger percentage of patients in 
the pooled AVX-470 dose groups (25.9\%) experienced clinical response when compared with placebo $(11.1 \%)$. The percentage of patients who experienced adverse events remained less than that observed in the placebo group. Future studies are, however, still required to evaluate the effects of higher doses and longer treatment duration on disease outcome.

\section{ANTI-ADHESION AGENTS}

The infiltration of leukocytes in the gut mucosa plays an important part in the pathogenesis of IBD. This process is mediated in part by interactions between specific molecules on the lymphocytes (integrins) and their ligands on the gut cells (mucosal vascular addressin cell adhesion molecule-1, MAdCAM-1) [6]. The blockade of these molecules inhibits the migration of the cells. The first drug tested for IBD was natalizumab which blocks the $\alpha 4$ subunit of several integrins on lymphocytes. Among others, it is responsible for the immune response in the gut and the central nervous system. The effectiveness of the drug was shown for both induction and maintenance therapy [7]. Nevertheless, the therapy was accompanied by a significant increase in the risk for progressive multifocal leukoencephalopathy (PML), a central nervous system infection caused by the JC virus. The second generation of anti-adhesion agents were developed to achieve more gut specificity. Vedolizumab was first to be approved by the US Food and Drug Administration (FDA) for Crohn's disease (CD) and UC. This agent blocks both subunits of the gut-specific MAdCAM-1, $\alpha 4$ and $\beta 7$, hence achieving a gut-selective effect. Several randomized controlled trials (RCTs) have displayed the effect of the drug in both CD (GEMINI II [8]) and UC (GEMINI I [9]) patients. To date, there have been no described reports of PML related to vedolizumab exposure, despite active screening both in clinical trials and day-to-day practice. Considering the safety profile of the two drugs, natalizumab is currently used scarcely, and only in patients with negative serology for the JC virus.

AJM300 is a small molecule, administered orally, which inhibits the $\alpha 4$ integrin subunit as well. In a recently published phase 2 a study, 102 patients with moderately active UC were treated with placebo or AJM300 at a dosage of $960 \mathrm{mg}$ three times daily. The primary endpoint, clinical response at 8 weeks, was observed in $62.7 \%$ and $25.5 \%$ of patients in the treatment and placebo groups, respectively $(\mathrm{OR}=5.35$, $p=0.0002)$. In the AJM300 group, clinical remission was $23.5 \%$ and mucosal healing was $58.8 \%$ versus $3.9 \%(p=0.0099)$ and $29.4 \%$ $(p=0.0014)$ in the placebo groups. No serious adverse events were identified. Specifically, no cases of PML have been reported to date [10]. Currently, there is an ongoing phase 3 study being conducted in Japan (ClinicalTrials.jp identifier 152862).

AMG 181 (abrilumab) is an IgG2 human monoclonal antibody that targets the $\alpha 4 \beta 7$ heterodimer, hence blocking the interaction with the MAdCAM-1 receptor. The first human study was conducted in 68 healthy subjects and in 4 subjects with active UC (3 active drug, 1 placebo), investigating its pharmacokinetic properties [11]. The UC patients treated with the drug achieved remission with mucosal healing at different time points. No treatmentrelated serious adverse events were observed. After several other pharmacokinetic (PK) and pharmacodynamic (PD) studies were done [12], AMG 181 was studied in IBD patients in phase $2 \mathrm{~b}$ clinical trials with preliminary data reported to date in the form of abstracts. In CD, patients were recruited to receive subcutaneous placebo, $21 \mathrm{mg}, \quad 70 \mathrm{mg}$, and $210 \mathrm{mg}$ every 4 weeks. Despite the absence of statistical significance, higher rates of remission and response were observed in the active treatment arms at week 12 , particularly in patients with prior failure of TNF antagonists assigned to the $210 \mathrm{mg}$ abrilumab group $(24.8 \%$ and $37.4 \%$, respectively, for the treatment group and $8.2 \%$ and $14.2 \%$ in the placebo group) [13]. The drug was similarly studied in 354 patients with moderate-to-severe UC [14]. Combined remission rates (the primary endpoint for the study) were $1.6 \%, 2.9 \%$, $13.5 \%$, and $13.4 \%$ in the $7,21,70$, and $210 \mathrm{mg}$ abrilumab arm, respectively, versus $4.4 \%$ in the placebo arm. The $p$ value was less than 0.1 for the $70 \mathrm{mg}$ and $210 \mathrm{mg}$ versus placebo. Interestingly, efficacy did not appear to correlate with 
peripheral target coverage or changes in $\alpha 4 \beta 7$ high $\mathrm{T}$ cells. For both studies, adverse events were balanced among groups through week 24, with no cases of PML or mortalities reported.

Etrolizumab is a humanized monoclonal antibody that selectively binds the $\beta 7$ subunit and hence blocks both $\alpha 4 \beta 7$ and $\alpha \mathrm{E} \beta 7$ integrins in the intestine. The drug antagonizes the recruitment of the lymphocytes as well as the retention of cells in the intraepithelial compartment. The safety and pharmacology of etrolizumab were evaluated in a randomized phase 1 study in patients with moderate-tosevere UC [15]. In 2014, a phase 2 study was conducted in 124 patients with moderate-tosevere UC ( $2 / 3$ anti-TNF experienced), receiving one of two doses of etrolizumab subcutaneously (100 mg at weeks 0,4 , and 8 ; or $420 \mathrm{mg}$ loading dose at week 0 , followed by $300 \mathrm{mg}$ at weeks 2 , 4 , and 8) or placebo. After 10 weeks of therapy, $21 \%$ in the $100 \mathrm{mg}$ group $(p=0.004)$ and $10 \%$ in the $300 \mathrm{mg}$ plus loading dose group $(p=0.048)$ attained clinical remission versus no patients in the placebo arm [16]. Adverse events occurred at a similar frequency in all three groups. Another study showed a histologic improvement (decrease of 6.9 points in the Robarts histopathology index) in the treatment group versus 1.5 in the placebo group $(p=0.015)$ [17]. A study comparing the efficacy and safety of etrolizumab with adalimumab and placebo in participants with UC (anti-TNFnaive) is currently ongoing (ClinicalTrials.gov Identifier NCT02163759).

The MAdCAM molecule on the vascular endothelium in the intestinal lamina propria is another therapeutic target. PF-00547659 is a highly specific fully human anti-MAdCAM IgG2 antibody. In one RCT from 2011, the safety and preliminary efficacy of this drug were investigated in 80 patients with active UC. Patients received single or multiple (three doses, 4-week intervals) doses of PF-00547659, 0.03-10 mg/kg IV/SC, or placebo. No obvious drug-related side effects were observed in the PF-00547659 group. Overall the response rate to PF-00547659 at 4 and 12 weeks was $52 \%$ and $42 \%$, respectively, compared to $32 \%$ and $21 \%$ with placebo, respectively [18]. The TURANDOT study [19], a phase 2, randomized, double-blind, placebo- controlled trial, which included 357 moderateto-severe UC patients $(57 \%$ had previously failed anti-TNF), studied the efficacy and safety of PF-00547659. Remission rates at week 12 were significantly higher in three of four active treatment groups compared to the placebo group (7.5 mg, $11.3 \% ; 22.5 \mathrm{mg}, 16.7 \%$; and $75 \mathrm{mg}, 15.5 \%)$. A total of $5.5 \%, 14.1 \%, 1.4 \%$, $4.1 \%$, and $4.3 \%$ of patients in the placebo, $7.5 \mathrm{mg}, 22.5 \mathrm{mg}, \quad 75 \mathrm{mg}$, and $225 \mathrm{mg}$ arms experienced severe adverse events. No safety signal was observed for the study drug. The OPERA study [20], a phase 2 trial of CD patients with a history of failure or intolerance to antiTNF and/or immunosuppressant drugs, showed a nominal difference in Crohn's Disease Activity Index (CDAI-70) response between PF00547659 and placebo at week 12, without reaching statistical significance. Given the length of follow-up and time to achieve remission in the vedolizumab studies for $C D$, the time to achieve remission may be the reason behind the failure of the study. The maintenance parts of the phase 2 studies have recently been completed and results are awaited [21].

\section{MODULATION OF INFLAMMATORY CYTOKINES}

\section{Anti-Interleukin-12/23}

IL-12 and IL-23 are cytokines that take part in the proinflammatory state in $\mathrm{CD}$, by stimulating proliferation of Th1 and Th17. Ustekinumab is a fully human, IgG1 antibody against the p40 subunit, which is shared by the two cytokines [22]. Its efficacy in treating psoriasis is well proven [23]. Phase 3 studies had described the efficacy of ustekinumab in moderate-tosevere CD [24]. In patients who met the criteria for primary or secondary nonresponse to TNF antagonists or had unacceptable side effects (UNITI-1), response rates at week 6 were significantly higher among those receiving either $130 \mathrm{mg}$ or $6 \mathrm{mg} / \mathrm{kg}$, compared to placebo $(34.3 \%, 33.7 \%$, and $21.5 \%$, respectively; $p$ $\leq 0.003)$. In patients who failed other treatment options but did not meet the criteria above (UNITI-2), clinical response was seen in 51.7\%, 
$55.5 \%$, and $28.7 \%$, respectively; $p<0.001$ ). In the groups receiving maintenance doses of ustekinumab (IM-UNITI) every 8 or 12 weeks, $53.1 \%$ and $48.8 \%$, respectively, were in remission at week 44 , compared to $35.9 \%$ of those receiving placebo $(p=0.005$ and $p=0.04$, respectively). Within each trial, adverse event rates were similar among the treatment groups. Two retrospective observational studies have also confirmed the efficacy of the drug for antiTNF-resistant disease, demonstrating a 65\% [25] and $81 \%$ [26] clinical response rate. The latter also demonstrated an endoscopic response in $77 \%$ of the patients in 3 months. A recent Cochrane review analyzed the pooled data from the different studies, demonstrating a statistically significant difference in remission rates [27]. At week 6, 84\% (764/914) of ustekinumab patients failed to enter remission compared to 90\% (367/406) of placebo patients (RR 0.92). Subgroup analysis showed a statistically significant difference for the $6 \mathrm{mg} / \mathrm{kg}$ dose group (moderate-quality evidence). As in the individual studies, there were no statistically significant differences in the incidence of adverse events, serious adverse events, or withdrawal due to adverse events. Infections were the most common adverse event in ustekinumab patients. Worsening of $C D$ and serious infections were the most common serious adverse events. The advantage of the unique mechanism of the drug was also demonstrated in patients with anti-TNF-related psoriasiform lesions in which nine patients were successfully treated with ustekinumab (response rate 100\%) [28]. A study to evaluate the safety and efficacy of ustekinumab in moderate-to-severe UC (UNIFI) is currently ongoing (ClinicalTrials.gov Identifier NCT02407236).

MEDI2070 (brazikumab) is a fully human antibody that blocks p19, a subunit of IL-23, and hence has no effect on IL-12 [29]. The efficacy of the drug was recently investigated in a phase 2a study [30]. Among 59 Crohn's disease patients treated with the drug, $49.2 \%$ had a clinical response at week 8 versus $26.7 \%$ of the placebo group $(p=0.01)$, with no significant difference in clinical remission. All subjects had previously received at least one anti-TNF agent. A composite outcome of clinical effect and at least a 50\% reduction from baseline fecal calprotectin (FCP) or C-reactive protein (CRP) was achieved in $42.4 \%$ with MEDI2070 versus $10.0 \%$ with placebo $(p<0.001)$. Clinical response (defined as CDAI decrease of 100 points from baseline) at week 24 occurred in $53.8 \%$ of patients who continued to receive the drug in an open-label regimen. The treatment also significantly decreased FCP and CRP from baseline compared to placebo at weeks 8 and 12. However, there were no endoscopic or radiologic evaluations of the bowel. The most common adverse events were headache and nasopharyngitis. Interestingly, higher baseline serum concentrations of IL-22, a cytokine whose expression is induced by IL-23, were associated with a greater likelihood of response to MEDI2070 compared to placebo. A phase $2 b$ study looking at induction and maintenance with different doses and administration regimens is currently ongoing (ClinicalTrials.gov Identifier NCT02574637).

Another antibody targeting IL-23 by binding the p19 subunit and blocking the cytokine activating the receptor is risankizumab. In a recently published study, 121 moderate-to-severe CD patients (>90\% anti-TNF-experienced) were randomized to intravenously receive $200 \mathrm{mg}$ or $600 \mathrm{mg}$ risankizumab or placebo, at weeks 0,4 , and 8 [31]. The primary outcome was clinical remission (CDAI $<150$ ) at week 12 , which was achieved in $24 \%$ of 41 patients who received $200 \mathrm{mg}(p=0.31)$ and $37 \%$ of 41 patients who received the $600 \mathrm{mg}$ dose $(p=0.025)$. The overall adverse events rate was not different between the study group and placebo. The most common adverse event was nausea and most common serious adverse event was worsening of underlying CD. No deaths had occurred. An extension of the data was recently presented showing 62/121 patients in clinical remission at week 26 [32]. At week 52, 71\% of patients (44/62) had clinical remission and 80\% had clinical response. The rate of endoscopic response and remission at week 52 was $54.8 \%$ and $35.5 \%$, respectively. A phase 3 study looking at induction and maintenance therapy with risankizumab for moderate-to-severe $\mathrm{CD}$ is currently active and recruiting (ClinicalTrials.gov Identifier NCT03105128). A direct comparison 
was done between risankizumab and ustekinumab in a population of patients with psoriasis and demonstrated a superior clinical response in the IL-23-selective risankizumab. At week 12, the percentage of patients with at least a $90 \%$ reduction in the Psoriasis Area and Severity Index score was 77\% (64/83) for risankizumab (pooled doses), compared to $40 \%$ (16/ 40) for ustekinumab $(p<0.001)$ [33]. Whether or not these data are applicable to IBD is yet to be determined.

\section{TGF-BETA (MONGERSEN)}

CD patients exhibit aberrant activity of the suppressive cytokine transforming growth factor (TGF) $\beta 1$ as a result of high levels of Smad7, an intracellular protein that binds to the cytokine's receptor and prevents downstream signaling. Knockdown of Smad7 restores TGF- $\beta 1$ activity, with the downstream effect of inhibiting inflammatory cytokine production. Mongersen (GED-0301) is an oral antisense oligonucleotide that binds and inactivates SMAD7 RNA, leading to restoration of TGF- $\beta 1$ signaling [34]. The first phase 2 RCT, published in 2015 , evaluated the efficacy of mongersen in the treatment of $160 \mathrm{CD}$ patients. Clinical remission on day 15 (the primary endpoint) was achieved in $55 \%$ and $65 \%$ of the $40 \mathrm{mg}$ and $160 \mathrm{mg}$ groups, respectively, compared to $10 \%$ of the placebo group $(p<0.001)$ [35]. CRP normalization was achieved on day 15 in $4 \%$ of the placebo group, $22 \%$ in the $10 \mathrm{mg}$ group, $18 \%$ in the $40 \mathrm{mg}$ group, and $18 \%$ in the $160 \mathrm{mg}$ group. A phase 3 clinical trial evaluating the clinical and endoscopic effect as well as safety profile of mongersen in patients with $\mathrm{CD}$ (REVOLVE trial) was recently discontinued as a result of futility $[36,37]$.

\section{INTRACELLULAR SIGNALING}

The Janus kinase/signal transducer and activator of transcription (JAK/STAT) signaling pathway represents a new target in IBD. Multiple inflammatory cytokines known to have a role in IBD pathogenesis utilize the JAK pathway.
Tofacitinib is a non-selective inhibitor of the JAK family, influencing mostly JAK1 and JAK3 [38]. Its effectiveness for rheumatoid arthritis has been demonstrated in several pivotal studies both as monotherapy [39] and in combination with an immunomodulator [40]. The first IBD phase 2 study was published in 2012 evaluating tofacitinib in different doses for treatment of moderate-to-severe UC [41]. The primary outcome, clinical response at 8 weeks (defined as an absolute decrease from baseline Mayo score of $\geq 3$ with an accompanying decrease in the rectal bleeding subscore), occurred more in the treatment group only in the higher dose of $15 \mathrm{mg}$ (78\% as compared with $42 \%$ of patients in the placebo group; $p<0.001)$. Clinical remission at week 8 was dose-dependent, occurring in $13 \%, 33 \%, 48 \%$, and $41 \%$ of patients receiving tofacitinib at a dose of $0.5 \mathrm{mg}$ $(p=0.76), 3 \mathrm{mg}(p=0.01), 10 \mathrm{mg}(p<0.001)$, and $15 \mathrm{mg}(p<0.001)$, respectively, compared to $10 \%$ of patients receiving placebo. Effectiveness was also demonstrated in two phase 3 induction studies, OCTAVE 1 and 2, and the maintenance study, OCTAVE Sustain [42]. At week 8, patients receiving tofacitinib $10 \mathrm{mg}$ BID achieved significantly higher rates of remission and mucosal healing in both studies versus placebo $(18.5 \% / 16.6 \%$ and $31.1 \% / 28.4 \%$ versus $8.2 \% / 3.6 \%$ and $15.6 \% / 11.6 \%$, respectively). Tofacitinib was the first drug to show similar efficacy in both anti-TNF alpha-experienced and anti-TNF alpha-naïve patients participating in the trials. In the OCTAVE Sustain trial, remission at 52 weeks occurred in $34.3 \%$ of the patients in the $5 \mathrm{mg}$ group and $40.6 \%$ in the $10 \mathrm{mg}$ group versus $11.1 \%$ in the placebo group ( $p<0.001$ for both comparisons). Mucosal healing rate was higher in the treatment groups at 52 weeks as well, when compared to placebo (37.4\%, 45.7\%, and $13.1 \%$, respectively). Overall, there was no difference in the rate of adverse events between treatment groups and placebo in both induction and maintenance trials (including serious adverse events). However, the rates of overall infections and serious infections were higher with tofacitinib versus placebo. In the OCTAVE Induction trial, herpes zoster infection occurred in five patients in the $10 \mathrm{mg}$ group and in one patient in the placebo group. 
In the OCTAVE Sustain trial, herpes zoster infection occurred in three patients $(1.5 \%)$ in the $5 \mathrm{mg}$ group, 10 patients $(5.1 \%)$ in the $10 \mathrm{mg}$ group, and one patient $(0.5 \%)$ in the placebo group. No cases of herpes zoster infection were considered serious adverse events or resulted in treatment discontinuation. Large cohort studies of rheumatoid arthritis (RA) patients demonstrated higher rates of infection and malignancy. The most commonly observed infections were pneumonia, herpes zoster, and urinary tract infections [43, 44]. Dose-related increases in low-density lipoprotein (LDL) cholesterol and high-density lipoprotein (HDL) levels have been observed in tofacitinib studies done in IBD patients, which resolved after drug cessation [41]. However, no increase in cardiovascular morbidity was found. Some studies suggest that despite the increase in cholesterol level, there was no significant change in the number of small dense LDL particles, which are considered to be more atherogenic than both large particles and oxidized LDL [45]. In fact, tofacitinib decreased carotid atherosclerosis in RA patients [46], and attenuated atherosclerosis and foam cell formation in an atherogenic murine model [47]. On the basis of clinical trial data from more than 6000 patients, which included more than 20,000 patient-years of tofacitinib exposure over a period of over 8 years, an increase in LDL and HDL levels was reported without an increased risk of cardiovascular events [44]. Recently, the FDA has approved the use of tofacitinib in patients with UC.

The results of a phase 2 study for the treatment of CD were less encouraging. There was no difference in the remission or response rates after 4 weeks of treatment. Nevertheless, there was a reduction in the CRP and FCP levels from baseline with the higher dose, not to mention the relatively high rate of response in the placebo group (46\%) [48]. Two phase $2 \mathrm{~b}$ studies for establishing the efficacy of tofacitinib for induction and maintenance therapy of CD also failed to reach their primary endpoint after long-term follow-up [49].

Filgotinib is another orally administered JAK inhibitor, 30 times more selective for JAK1 over JAK2. The drug was also found to be effective for RA [50, 51]. The FITZROY study, an RCT including 174 patients, meant to examine the efficacy and safety of filgotinib for the treatment of moderate-to-severe CD [52]. Sixty $(47 \%)$ of 128 patients in the filgotinib group achieved the primary endpoint (clinical remission at week 10) compared to $10(23 \%)$ of 44 patients in the placebo group $(p=0.008)$. The efficacy of filgotinib, including clinical remission, response, and Inflammatory Bowel Disease Questionnaire (IBDQ), was shown in CD patients independently of their prior anti-TNF exposure [53]. The effect was much less dramatic among patients with previous exposure to anti-TNF alpha therapy (29\% versus 37\% among treatment and placebo group, respectively). There was a greater proportion of patients achieving endoscopic remission at week 10 in the filgotinib versus the placebo group, but that difference did not reach statistical significance. An extension maintenance study demonstrated that at week 20 (while continuing $200 \mathrm{mg}$ once daily), $71 \%$ of initial responders showed clinical remission and 79\% showed clinical response, while maintaining improvement in quality of life [54].As for adverse events, no change was seen in blood counts or liver enzymes. There was an $11 \%$ increase in mean HDL and a $12 \%$ increase in mean LDL at week 20 , with a $4 \%$ and $13 \%$ increase in the placebo group, respectively.

The efficacy and safety of upadacitinib, another oral selective JAK1 inhibitor, are currently being studied in patients with moderateto-severe CD. Results in 180 patients who completed 16 weeks of induction in a phase 2 study were recently published [55]. Significantly more patients achieved clinical remission with $6 \mathrm{mg}$ BID. A significant endoscopic improvement was found as well with a dose-response ratio using a dose of $12 \mathrm{mg}$ BID and higher.

\section{ANTI-TRAFFICKING MOLECULES}

Sphingosine is a molecule that makes up sphingomyelin, a structural protein in the lipid bilayer of human cells. Its metabolite sphingosine-1 phosphate (S1P) is involved in cellular signaling pathways via its downstream effectors [56-58]. Ozanimod (RPC1063) is an oral agent which acts as a selective agonist and modulator 
of S1PR subtypes 1 and 5 [59]. Upon binding S1PR subtype 1, ozanimod upregulates the S1P gradient, leading to a negative feedback on the expression of the receptor itself, causing its degradation via the ubiquitin-proteosome pathway. Loss of downstream S1P effects leads to sequestration of lymphocytes in peripheral lymphoid organs, hindering their trafficking to sites of inflammation. This effect is reversible upon discontinuing the drug, lasting approximately 14 days. The relationship between the S1P effect and heightened inflammation may be bidirectional. New data suggest that chronic inflammation itself may modulate the expression of S1PR subtype 1, further elucidating events in the pathogenesis of IBD [60]. The role of S1P gradient in regulating endothelial permeability may be an additional factor to the anti-leukocyte trafficking properties of S1P agonists, potentiating their use in chronic inflammatory diseases. The safety and efficacy of ozanimod have been evaluated in TOUCHSTONE, a phase 2, double-blind, placebo-controlled clinical trial in patients with UC $(n=197)$ [61]. Only $20 \%$ were previously exposed to anti-TNF. Patients received induction therapy with daily orally administered ozanimod ( $0.5 \mathrm{mg}$ or $1 \mathrm{mg}$ ) or placebo. At week 8 , clinical remission (Mayo score $\leq 2$; no subscore $>1$ ) was achieved in $16 \%$ of patients in the $1 \mathrm{mg}$ ozanimod arm. This rate was significantly higher $(p=0.048)$ when compared to placebo. It continued to increase in the maintenance period with a rate of $21 \%$ at week 32 $(p=0.01)$. Secondary outcomes, namely mucosal healing and histologic remission, were generally significantly improved as well. The longterm effect was also demonstrated with $88.2 \%$ of the patients entering the open-label extension (OLE) trial. These patients had a rectal bleeding subscore of 0 at week 104 [62].

Adverse events related to S1P modulation may involve bradycardia, increased risk for malignancies and infections, pulmonary dysfunction, decreased blood pressure, cardiac conduction abnormalities, and liver injury [58]. In the TOUCHSTONE trial, there were no significant differences in reported adverse events among the three groups, with the most common adverse events being UC flare, anemia, and headache. There was one incidence of asymptomatic transient self-resolving bradycardia in the ozanimod group [61]. Patients on ozanimod in the OLE trial experienced adverse events such as UC flare, anemia, upper respiratory tract infections, nasopharyngitis, and transaminase elevation. A phase 3 study for evaluation of induction and maintenance therapy for UC is currently ongoing.

\section{OTHER TREATMENTS}

Toll-like receptors (TLR) belong to the family of pattern recognition receptors. They play a key role in innate immunity, allowing host cells to recognize pathogenic molecules. Activation of the TLR-9 receptor has been proposed to stimulate intestinal mucosal healing [63], suggesting a potential therapeutic target in IBD. The DNAbased immunomodulatory sequence DIMS0150 is an oligonucleotide that acts as an agonist to TLR-9. It has been developed in the form of a topical agent, intended as an add-on therapy in colitis. The safety and efficacy of DIMS0150 in UC have been investigated in the COLLECT study in Europe, a phase 3, randomized, doubleblind, placebo-controlled clinical trial [64]. Patients enrolled $(n=131)$ had steroid-refractory moderate-to-severe UC (Clinical Activity Index $[\mathrm{CAI}] \geq 9$; endoscopic Mayo score $\geq 2$; about $40 \%$ previously exposed to anti-TNF). Patients continued taking oral steroids during the trial and were randomized to either DIMS0150 or placebo, delivered topically via endoscopy as two doses 4 weeks apart. In the intent-to-treat population, clinical remission $(\mathrm{CAI} \leq 4)$ at weeks 4 and 12 did not reach clinical significance. However, when combined with mucosal healing (endoscopic Mayo score $\leq 1$ ), clinical remission was significantly higher in patients treated with DIMS0150 compared to placebo $(p=0.02)$. It was also observed that DIMS0150 exhibited improved outcomes as assessed by symptomatic remission (absence of blood in stool and number of weekly stools $<$ 
$35)$ at week $4(p=0.02)$. This led the investigators to consider patient-reported outcomes when evaluating the efficacy of DIMSO150 [65]. They demonstrated that, compared to placebo, patients on DIMS0150 had significantly better outcomes $(p<0.05)$ at weeks 4 and 12 (assessed by absence of blood in the stool and mean daily stool frequency $<4$ ). In terms of safety, the sample size of patients was not large enough to observe significant differences. A proposed mechanism for the efficacy of DIMS0150 in patients with refractory UC is via improved sensitization to steroids $[66,67]$.

Phosphatidylcholine (PC) is a normal component of colonic mucus that becomes depleted in patients with UC [68]. Repletion of the intestinal layer with PC strengthens its permeability and integrity in animal models of colitis [69]. The use of PC was investigated in patients with UC $(n=156)$ in a multicenter, randomized, double-blind, placebo-controlled trial [70]. A modified release form of PC (LT-02) was used. Patients randomized to the highest dose of LT02 (3.2 g/day) showed significant reduction in their Simple Clinical Colitis Activity Index (SCCAI) when compared to placebo $(p=0.03)$. Although mucosal healing did not attain significant improvement, histologic remission was markedly higher in patients on LT-02. It was estimated that in patients with mesalazine-refractory UC, the number needed-to-treat with PC was 6 to achieve remission and 4 to achieve clinical response. This oral agent is currently in phase 3 trials (NCT02280629).

Phosphodiesterase 4 (PDE4) is one of several proteins which catalyze the breakdown of cyclic AMP (cAMP), which regulates a significant part of the intracellular inflammatory cascade. Thus, increases in intracellular cAMP due to PDE4 inhibition downregulates the immune response [71]. Apremilast is a PDE4 inhibitor currently approved for use in psoriasis [72]. The results of a phase 2 study, demonstrating its effectiveness for UC, were recently presented [73]. Patients treated with apremilast had improvement in symptoms, endoscopy, biomarkers, and mucosal healing compared with placebo. The company studying apremilast in UC recently announced that they are reconsidering this development program [74].

\section{GUT MICROBIOME MANIPULATIONS}

The correlation between gut microbiota alterations and the immune response of the gut mucosa has long been known. The cause and effect relationship is not entirely understood, but changes in the composition of gut bacteria have an influence on the inflammatory response. The clinical effect of gut microbiome manipulation has been increasingly studied during the past few years. A recent meta-analysis reviewing 53 studies that comprised 661 IBD patients concluded that $36 \%$ of UC patients, $50.5 \%$ of CD patients, and $21.5 \%$ of pouchitis patients undergoing fecal microbiota transplantation (FMT) achieved clinical remission. Furthermore, there was improved remission in UC patients that had a higher number of FMT infusions and if administered throughout the lower GI tract [75]. In 2015, Rossen et al. conducted an RCT, introducing two doses of FMT enterally through a nasoduodenal tube [76]. A total of 37 patients completed the primary endpoint assessment (composite of clinical remission and decrease in the endoscopic Mayo score at week 12). In the intention-to-treat analysis, 7 of 23 patients who received fecal transplants from healthy donors (30.4\%) and 5 of 25 controls $(20.0 \%)$ achieved the primary endpoint $(p=0.51)$. In the per-protocol analysis, no difference was found between the two groups. Another RCT by Moayyedi et al. examined the efficacy of FMT in patients with active mild-tomoderate UC [77]. This was done using weekly FMT or placebo via retention enema for 6 weeks. Nine patients in the treatment group (24\%) and two patients in the placebo group (5\%) were in clinical and endoscopic remission at 7 weeks $(p=0.03)$. Clinical response was achieved in 39\% $(15 / 38)$ of patients who received FMT in comparison to $24 \%(9 / 37)$ of patients receiving placebo. Stools from patients receiving FMT had greater microbial diversity, compared to baseline and to patients given placebo $(p=0.02)$. A recent study [78] described the effect of intense FMT, multidonor in origin, in patients with severe, resistant UC. This proof of concept study demonstrated a primary endpoint of steroid-free clinical remission and endoscopic remission or 
response in 11 of 41 (27\%) patients receiving FMT versus 3 of $40(8 \%)$ patients receiving placebo $(p=0.02)$. There was no difference in adverse events between the study arms. A current multicenter, randomized, double-blind, placebo-controlled trial is being conducted in patients with mild-to-moderate UC, where patients are transplanted with donor FMT enemas or autologous FMT (as placebo). Preliminary results indicate that $32 \%$ of patients achieve steroid-free remission versus $9 \%$ of the placebo group $(p=0.02)$, and $50 \%$ of patients receiving FMT achieve clinical remission in comparison to $17 \%$ of the placebo group $(p=0.02)$. The frequency of serious adverse events did not differ between the two groups [79]. The clinical effect of FMT on the course of IBD is significantly lower than the one achieved in the case of Clostridium difficile infections. Nevertheless, the complexity of the disease and the potential side effects of other lines of treatments make FMT a promising therapy to develop in IBD. More RCTs are needed to better understand this treatment modality in IBD, its efficacy, safety, and long-term effect on the recipient's microbiome.

\section{BIOSIMILARS}

The development of new treatment options along with transition of therapy from immunosuppression and surgical intervention to targeted, small molecules, or protein-based drugs has created a significant financial problem. This and the termination of the patent period for the first biologics, infliximab and adalimumab, have created the possibility of developing similar drugs. As a result of the complexity of the protein-based drug, and its production process, it is not possible to produce a completely similar drug. Hence, these are considered to be biosimilars, which represent the minor differences between them and the originator. In order to be considered a biosimilar, the drug needs to present similarity in efficacy and safety in clinical trials for a single indication alone. This can be later extrapolated for the other approved indications [80]. Initially, a concern was raised regarding the safety of switching between drugs. Recent data, however, have proven the efficacy and safety of switches between originator and biosimilar drug [81-83]. Currently, biosimilars are approved for infliximab and adalimumab $[84,85]$.

\section{NOVEL CORTICOSTEROIDS}

Budesonide is a second-generation corticosteroid that has minimal systemic activity due to first-pass hepatic metabolism. Two formulations of budesonide are currently available, a pH-dependent release formulation and an extended release tablet, which uses a Multi-Matrix System (MMX) to target delivery in the colon. In the USA, only budesonide MMX is currently indicated for induction of remission in mild-tomoderate UC. Multiple RCTs to date have demonstrated that 3-9 mg of budesonide MMX is well tolerated, induces a significant improvement in patients when compared to placebo, and has a safety profile similar to placebo, with a higher incidence of corticosteroid-related adverse effects [86].

In the CORE I and CORE II, phase 3, doubleblind, placebo-controlled, multicenter RCTs, conducted on patients with mild-to-moderate UC, budesonide MMX $9 \mathrm{mg}$ was found to be more effective than mesalamine and placebo at 8 weeks of treatment $[87,88]$. Pooled safety data showed that adverse effects occurred at similar frequencies between the study groups [89]. Budesonide foam has also been shown to be effective for the induction of remission in UC, when compared to placebo. It is safe and has a low incidence of effects on the hypothalamic-pituitary-adrenal axis [90]. Overall, second-generation corticosteroids exhibit a favorable safety profile in patients with mild-tomoderate UC; however, longer-term data beyond 8 weeks remain unavailable.

\section{NOVEL COMBINATIONS}

\section{Calcineurin Inhibitors and Vedolizumab}

Cyclosporine and tacrolimus are immunosuppressants which inhibit the activity of calcineurin and, in turn, inhibit $\mathrm{T}$ cell activation. Their activity as a rescue therapy for the 
Table 1 New therapies for IBD

\begin{tabular}{|c|c|c|c|c|}
\hline Treatment modality & Target & Type & $\begin{array}{l}\text { Development } \\
\text { status }\end{array}$ & Indication \\
\hline \multicolumn{5}{|l|}{ New anti-TNF } \\
\hline AVX-470 & TNF & Polyclonal anti-TNF AB & Phase 1 trials & $\begin{array}{l}\text { Moderate-to-severe } \\
\text { UC }\end{array}$ \\
\hline \multicolumn{5}{|l|}{ Anti-adhesion agents } \\
\hline AJM300 & $\alpha 4$ integrin & Oral $\alpha 4$ integrin antagonist & Phase 3 trials & UC \\
\hline AMG 181 & $\begin{array}{c}\alpha 4 \beta 7 \text { integrin } \\
\text { MAdCAM }\end{array}$ & Monoclonal AB & Phase 2 trials & $\mathrm{UC}$ and $\mathrm{CD}$ \\
\hline Etrolizumab & $\beta 7$ integrin & Monoclonal $\mathrm{AB}$ & Phase 3 trials & $\mathrm{UC}$ and $\mathrm{CD}$ \\
\hline PF-00547659 & MAdCAM-1 & Monoclonal $\mathrm{AB}$ & Phase 2 trials & $\mathrm{UC}$ and $\mathrm{CD}$ \\
\hline \multicolumn{5}{|l|}{ Cytokine blockage } \\
\hline Ustekinumab & $\begin{array}{l}\text { IL-12/IL-23 } \\
\text { p40 subunit }\end{array}$ & Monoclonal $\mathrm{AB}$ & FDA approved & $\mathrm{CD}$ \\
\hline $\begin{array}{l}\text { MEDI2070 } \\
\text { (brazikumab) }\end{array}$ & $\begin{array}{l}\text { IL-23 } \\
\text { P19 subunit }\end{array}$ & Monoclonal $\mathrm{AB}$ & Phase $2 \mathrm{~b}$ trials & $\mathrm{CD}$ \\
\hline Risankizumab & $\begin{array}{l}\text { IL-23 } \\
\text { P19 subunit }\end{array}$ & Monoclonal $\mathrm{AB}$ & Phase 3 trials & $\mathrm{UC}$ and $\mathrm{CD}$ \\
\hline \multicolumn{5}{|l|}{ JAK inhibitors } \\
\hline Tofacitinib & Janus kinase & Oral JAK inhibitor & $\begin{array}{l}\text { FDA approved } \\
\text { Phase } 2 \mathrm{~b} \text { trials }\end{array}$ & $\begin{array}{l}\mathrm{UC} \\
\mathrm{CD}\end{array}$ \\
\hline Filgotinib & Janus kinase 1 & Oral JAK inhibitor & Phase 3 trials & $\mathrm{CD}$ \\
\hline Upadacitinib & Janus kinase 1 & Oral JAK inhibitor & Phase 2 trials & $\mathrm{CD}$ \\
\hline FMT & Gut microbiome & Feces & Phase 2 trials & $\mathrm{UC}$ \\
\hline \multicolumn{5}{|c|}{ Anti-trafficking molecules } \\
\hline $\begin{array}{l}\text { Ozanimod } \\
\text { (RPC1063) }\end{array}$ & S1P receptor agonist & Oral receptor modulator & $\begin{array}{l}\text { Phase } 3 \text { trials } \\
\text { Phase } 2 \text { trials }\end{array}$ & $\begin{array}{l}\mathrm{UC} \\
\mathrm{CD}\end{array}$ \\
\hline \multicolumn{5}{|l|}{ TLR agonists } \\
\hline DIMS0150 & TLR-9 & Oligonucleotide & Phase 3 trials & UC \\
\hline \multicolumn{5}{|l|}{ Phosphatidylcholine } \\
\hline LT-02 & Mucosal barrier & Oral phospholipid & Phase 3 trials & $\mathrm{UC}$ \\
\hline \multicolumn{5}{|l|}{ PDE4 inhibitors } \\
\hline $\begin{array}{l}\text { Apremilast } \\
\text { TGF beta }\end{array}$ & Phosphodiesterase 4 & Oral PDE4 inhibitor & Phase 2 trial & UC \\
\hline
\end{tabular}


Table 1 continued

\begin{tabular}{lllll}
\hline Treatment modality & Target & Type & $\begin{array}{l}\text { Development } \\
\text { status }\end{array}$ & Indication \\
\hline Mongersen & SMAD7 & $\begin{array}{c}\text { SMAD7 antisense } \\
\text { oligonucleotide }\end{array}$ & $\begin{array}{c}\text { Withdrawn from } \\
\text { study }\end{array}$ & UC and CD \\
$\begin{array}{l}\text { Corticosteroids } \\
\text { Budesonide MMX }\end{array}$ & $\begin{array}{l}\text { Glucocorticoid } \\
\text { receptor }\end{array}$ & $\begin{array}{c}\text { Second-generation } \\
\text { corticosteroid }\end{array}$ & FDA approved & UC \\
\hline
\end{tabular}

$A B$ antibody, S1P sphingosine-1-phosphate

management of severe CD or UC was previously assessed. Traditionally, they have been used as a bridge to maintenance therapy with azathioprine or 6-mercapotpurine [91, 92]. As a result of safety issues regarding the long-term treatment with this drug group, other options were investigated as well. The administration of cyclosporine or tacrolimus as a bridge to vedolizumab therapy was assessed in a recently published study [93]. Most patients had active disease while beginning treatment with vedolizumab. Combination therapy of vedolizumab with either cyclosporine or tacrolimus was effective in both UC and CD patients. Endoscopically, mucosal healing was achieved in one of seven CD and four of seven UC patients. There were three serious adverse events noted, all associated with calcineurin inhibitors. These are preliminary data, but considering the established evidence of both treatments independently and the risk-benefit ratio from this combination, it will probably prove to be effective.

\section{CONCLUSIONS}

Various therapies are currently being developed for IBD. Although many treatment modalities have recently been approved, additional drugs commonly used for other indications are currently being investigated and will probably be part of the IBD treatment regimen in the coming years. Table 1 summarizes the different treatment modalities discussed in this paper, with emphasis on mode of action, target, and phase of development. Unfortunately, despite the recent advances and the increasing number of options in the physician's toolbox, there are still several limitations with our management of IBD. The main limitation is our inability to personalize the specific treatment to a specific patient. The lack of accurate biologic markers, used to predict the patient's response to the drug (despite some but partial progress in that field), may lead us to a less than optimal drug selection process. Nevertheless, with recent breakthroughs in understanding the etiologies of IBD, having access to numerous treatments with different targets offers the promise of better disease control and treatment for the IBD patient.

\section{ACKNOWLEDGEMENTS}

Funding. No funding or sponsorship was received for this study or publication of this article.

Authorship. All named authors meet the International Committee of Medical Journal Editors (ICMJE) criteria for authorship for this article, take responsibility for the integrity of the work as a whole, and have given their approval for this version to be published.

Disclosures. Roni Weisshof received consultant fees from Janssen. Katia El Jurdi and Nada Zmeter have no relevant disclosures. David T. Rubin is a consultant and has received grant 
support from Abbvie, Genentech/Roche, Janssen, Takeda, Pfizer, Amgen, Samsung/Bioepis.

Compliance with Ethics Guidelines. This article is based on previously conducted studies and does not directly contain any studies with human participants or animals performed by any of the authors.

Data Availability. Data sharing is not applicable to this article as no datasets were generated or analyzed during the current study.

Open Access. This article is distributed under the terms of the Creative Commons Attribution-NonCommercial 4.0 International License (http://creativecommons.org/licenses/ by-nc/4.0/), which permits any noncommercial use, distribution, and reproduction in any medium, provided you give appropriate credit to the original author(s) and the source, provide a link to the Creative Commons license, and indicate if changes were made.

\section{REFERENCES}

1. Coskun M, Vermeire S, Nielsen $\mathrm{OH}$. Novel targeted therapies for inflammatory bowel disease. Trends Pharmacol Sci. 2017;38:127-42.

2. Sokol H, Seksik P, Cosnes J. Complications and surgery in the inflammatory bowel diseases biological era. Curr Opin Gastroenterol. 2014;30:378-84.

3. Baert F, Noman M, Vermeire S, et al. Influence of immunogenicity on the long-term efficacy of infliximab in Crohn's disease. $\mathrm{N}$ Engl J Med. 2003;348:601-8.

4. Harris MS, Hartman D, Lemos BR, et al. AVX-470, an orally delivered anti-tumour necrosis factor antibody for treatment of active ulcerative colitis: results of a first-in-human trial. J Crohns Colitis. 2016;10:631-40.

5. Hartman DS, Tracey DE, Lemos BR, et al. Effects of AVX-470, an oral, locally acting anti-tumour necrosis factor antibody, on tissue biomarkers in patients with active ulcerative colitis. J Crohns Colitis. 2016;10:641-9.

6. Strober W, Fuss IJ. Proinflammatory cytokines in the pathogenesis of inflammatory bowel diseases. Gastroenterology. 2011;140:1756-67.
7. Sandborn WJ, Colombel JF, Enns R, et al. Natalizumab induction and maintenance therapy for Crohn's disease. N Engl J Med. 2005;353:1912-25.

8. Sandborn WJ, Feagan BG, Rutgeerts P, et al. Vedolizumab as induction and maintenance therapy for Crohn's disease. N Engl J Med. 2013;369:711-21.

9. Feagan BG, Rutgeerts P, Sands BE, et al. Vedolizumab as induction and maintenance therapy for ulcerative colitis. N Engl J Med. 2013;369:699-710.

10. Yoshimura N, Watanabe M, Motoya S, et al. Safety and efficacy of AJM300, an oral antagonist of alpha4 integrin, in induction therapy for patients with active ulcerative colitis. Gastroenterology. 2015;149(1775-1783):e2.

11. Pan WJ, Kock K, Rees WA, et al. Clinical pharmacology of AMG 181, a gut-specific human anti-alpha4beta7 monoclonal antibody, for treating inflammatory bowel diseases. Br J Clin Pharmacol. 2014;78:1315-33.

12. Li H, Kock K, Wisler JA, et al. Prediction of clinical pharmacokinetics of AMG 181, a human anti-alpha 4 beta 7 monoclonal antibody for treating inflammatory bowel diseases. Pharmacol Res Perspect. 2015;3:e00098.

13. Sandborn WJ, Cyrille M, Hansen MB, et al. Efficacy and safety of abrilumab (AMG 181/MEDI 7183) therapy for moderate to severe Crohn's disease. Gastroenterology. 2017;152;S598.

14. Sandborn WJ, Cyrille M, Hansen MB, et al. Efficacy and safety of abrilumab in subjects with moderate to severe ulcerative colitis: results of a phase $2 \mathrm{~B}$, randomized, double-blind, multiple-dose, placebocontrolled study. Gastroenterology. 2017;152;S198.

15. Rutgeerts PJ, Fedorak RN, Hommes DW, et al. A randomised phase I study of etrolizumab (rhuMAb beta7) in moderate to severe ulcerative colitis. Gut. 2013;62:1122-30.

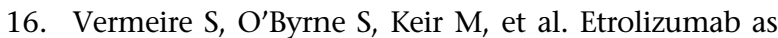
induction therapy for ulcerative colitis: a randomised, controlled, phase 2 trial. Lancet. 2014;384:309-18.

17. Feagan BG, De Hertogh G, Peyrin-Biroulet L, et al. Etrolizumab treatment improves histological activity as assessed by the Robarts histopathology index. Gastroenterology. 2017;152:S600.

18. Vermeire S, Ghosh S, Panes J, et al. The mucosal addressin cell adhesion molecule antibody PF00547,659 in ulcerative colitis: a randomised study. Gut. 2011;60:1068-75.

19. Vermeire S, Sandborn WJ, Danese S, et al. AntiMAdCAM antibody (PF-00547659) for ulcerative 
colitis (TURANDOT): a phase 2, randomised, double-blind, placebo-controlled trial. Lancet. 2017;390:135-44.

20. Sandborn WJ, Lee SD, Tarabar D, et al. Phase II evaluation of anti-MAdCAM antibody PF-00547659 in the treatment of Crohn's disease: report of the OPERA study. Gut. 2018;67:1824-35.

21. Shire. Long-term safety of PF-00547659 in ulcerative colitis. ClinicalTrials.gov. 2018. https:// clinicaltrials.gov/ct2/show/NCT01771809. Accessed 17 Jan 2018.

22. Sandborn WJ, Feagan BG, Fedorak RN, et al. A randomized trial of ustekinumab, a human interleukin-12/23 monoclonal antibody, in patients with moderate-to-severe Crohn's disease. Gastroenterology. 2008;135:1130-41.

23. Leonardi CL, Kimball AB, Papp KA, et al. Efficacy and safety of ustekinumab, a human interleukin$12 / 23$ monoclonal antibody, in patients with psoriasis: 76-week results from a randomised, doubleblind, placebo-controlled trial (PHOENIX 1). Lancet. $2008 ; 371: 1665-74$.

24. Feagan BG, Sandborn WJ, Gasink C, et al. Ustekinumab as induction and maintenance therapy for Crohn's disease. N Engl J Med. 2016;375:1946-60.

25. Wils P, Bouhnik Y, Michetti P, et al. Subcutaneous ustekinumab provides clinical benefit for two-thirds of patients with Crohn's disease refractory to antitumor necrosis factor agents. Clin Gastroenterol Hepatol. 2016;14(242-50):e1-2.

26. Harris KA, Horst S, Gadani A, et al. Patients with refractory Crohn's disease successfully treated with ustekinumab. Inflamm Bowel Dis. 2016;22:397-401.

27. MacDonald JK, Nguyen TM, Khanna R, et al. AntiIL-12/23p40 antibodies for induction of remission in Crohn's disease. Cochrane Database Syst Rev. 2016;11:CD007572.

28. Tillack C, Ehmann LM, Friedrich M, et al. Anti-TNF antibody-induced psoriasiform skin lesions in patients with inflammatory bowel disease are characterised by interferon-gamma-expressing Th1 cells and IL-17A/IL-22-expressing Th17 cells and respond to anti-IL-12/IL-23 antibody treatment. Gut. 2014;63:567-77.

29. Kock K, Pan WJ, Gow JM, et al. Preclinical development of AMG 139, a human antibody specifically targeting IL-23. Br J Pharmacol. 2015;172:159-72.

30. Sands BE, Chen J, Feagan BG, et al. Efficacy and safety of MEDI2070, an antibody against interleukin 23, in patients with moderate to severe
Crohn's disease: a phase 2a study. Gastroenterology. 2017;153(77-86):e6.

31. Feagan BG, Sandborn WJ, D'Haens G, et al. Induction therapy with the selective interleukin-23 inhibitor risankizumab in patients with moderateto-severe Crohn's disease: a randomised, doubleblind, placebo-controlled phase 2 study. Lancet. 2017;389:1699-709.

32. Feagan BG, Panes J, Ferrante M, et al. Risankizumab in patients with moderate to severe Crohn's disease: an open-label extension study. Lancet Gastroenterol Hepatol. 2018;3(10):P671-P680.

33. Papp KA, Blauvelt A, Bukhalo M, et al. Risankizumab versus ustekinumab for moderate-to-severe plaque psoriasis. N Engl J Med. 2017;376:1551-60.

34. Monteleone G, Fantini MC, Onali S, et al. Phase I clinical trial of Smad7 knockdown using antisense oligonucleotide in patients with active Crohn's disease. Mol Ther. 2012;20:870-6.

35. Monteleone G, Neurath MF, Ardizzone S, et al. Mongersen, an oral SMAD7 antisense oligonucleotide, and Crohn's disease. N Engl J Med. 2015;372:1104-13.

36. Celgene provides update on GED-0301 (mongersen) inflammatory bowel disease program. Business Wire. 2017. https://www.businesswire.com/news/home/ 20171019006519/en/Celgene-Update-GED-0301mongersen-Inflammatory-Bowel-Disease. Accessed 15 Jan 2018.

37. A randomized, double-blind, study to explore the effect of GED-0301 in subjects with active Crohn's 1102 disease. ClinicalTrials.gov. 2018. https:// clinicaltrials.gov/ct2/show/NCT02367183. Accessed 20 Jan 2018.

38. Flanagan ME, Blumenkopf TA, Brissette WH, et al. Discovery of CP-690,550: a potent and selective Janus kinase (JAK) inhibitor for the treatment of autoimmune diseases and organ transplant rejection. J Med Chem. 2010;53:8468-84.

39. Fleischmann R, Kremer J, Cush J, et al. Placebocontrolled trial of tofacitinib monotherapy in rheumatoid arthritis. $\mathrm{N}$ Engl J Med. 2012;367:495-507.

40. van Vollenhoven RF, Fleischmann R, Cohen S, et al. Tofacitinib or adalimumab versus placebo in rheumatoid arthritis. $\mathrm{N}$ Engl J Med. 2012;367:508-19.

41. Sandborn WJ, Ghosh S, Panes J, et al. Tofacitinib, an oral Janus kinase inhibitor, in active ulcerative colitis. N Engl J Med. 2012;367:616-24. 
42. Sandborn WJ, Su C, Sands BE, et al. Tofacitinib as induction and maintenance therapy for ulcerative colitis. N Engl J Med. 2017;376:1723-36.

43. Wollenhaupt J, Silverfield J, Lee EB, et al. Safety and efficacy of tofacitinib, an oral Janus kinase inhibitor, for the treatment of rheumatoid arthritis in open-label, longterm extension studies. J Rheumatol. 2014;41:837-52.

44. Cohen SB, Tanaka Y, Mariette X, et al. Long-term safety of tofacitinib for the treatment of rheumatoid arthritis up to 8.5 years: integrated analysis of data from the global clinical trials. Ann Rheum Dis. 2017;76:1253-62.

45. Wolk R, Armstrong EJ, Hansen PR, et al. Effect of tofacitinib on lipid levels and lipid-related parameters in patients with moderate to severe psoriasis. J Clin Lipidol. 2017;11:1243-56.

46. Kume K, Amano K, Yamada S, et al. Tofacitinib improves atherosclerosis despite up-regulating serum cholesterol in patients with active rheumatoid arthritis: a cohort study. Rheumatol Int. 2017;37:2079-85.

47. Wang Z, Wang S, Yun T, et al. Tofacitinib ameliorates atherosclerosis and reduces foam cell formation in apoE deficient mice. Biochem Biophys Res Commun. 2017;490:194-201.

48. Sandborn WJ, Ghosh S, Panes J, et al. A phase 2 study of tofacitinib, an oral Janus kinase inhibitor, in patients with Crohn's disease. Clin Gastroenterol Hepatol. 2014;12(1485-93):e2.

49. Panes J, Sandborn WJ, Schreiber S, et al. Tofacitinib for induction and maintenance therapy of Crohn's disease: results of two phase IIb randomised placebo-controlled trials. Gut. 2017;66:1049-59.

50. Kavanaugh A, Kremer J, Ponce L, et al. Filgotinib (GLPG0634/GS-6034), an oral selective JAK1 inhibitor, is effective as monotherapy in patients with active rheumatoid arthritis: results from a randomised, dose-finding study (DARWIN 2). Ann Rheum Dis. 2017;76:1009-19.

51. Westhovens R, Taylor PC, Alten R, et al. Filgotinib (GLPG0634/GS-6034), an oral JAK1 selective inhibitor, is effective in combination with methotrexate (MTX) in patients with active rheumatoid arthritis and insufficient response to MTX: results from a randomised, dose-finding study (DARWIN 1). Ann Rheum Dis. 2017;76:998-1008.

52. Vermeire S, Schreiber S, Petryka R, et al. Clinical remission in patients with moderate-to-severe Crohn's disease treated with filgotinib (the FITZROY study): results from a phase 2, double-blind, randomised, placebo-controlled trial. Lancet. 2017;389:266-75.

53. D'Haens GR, Schreiber S, Petryka R, et al. Efficacy of filgotinib, a selective Jak1 inhibitor, is independent of prior anti-TNF exposure: subgroup analysis of the phase 2 Fitzroy study in moderate-to-severe Crohn's disease. Gastroenterology. 2017;152;s597.

54. Vermeire S, Schreiber S, Petryka R, et al. Maintenance of clinical effect in patients with moderateto-severe Crohn's disease treated with filgotinib, a selective Jak1 inhibitor: exploratory 20-week data analysis of the phase 2 Fitzroy study. Gastroenterology. 2017;152;s601.

55. Sandborn WJ, Feagan BG, Panes J, et al. Safety and efficacy of ABT-494 (upadacitinib), an oral Jak1 inhibitor, as induction therapy in patients with Crohn's disease: results from Celest. Gastroenterology. 2017;152;s1308-9.

56. Spiegel S, Milstien S. Sphingosine-1-phosphate: an enigmatic signalling lipid. Nat Rev Mol Cell Biol. 2003;4:397-407.

57. Spiegel S, Milstien S. The outs and the ins of sphingosine-1-phosphate in immunity. Nat Rev Immunol. 2011;11:403-15.

58. Juif PE, Kraehenbuehl S, Dingemanse J. Clinical pharmacology, efficacy, and safety aspects of sphingosine-1-phosphate receptor modulators. Expert Opin Drug Metab Toxicol. 2016;12:879-95.

59. Scott FL, Clemons B, Brooks J, et al. Ozanimod (RPC1063) is a potent sphingosine-1-phosphate receptor-1 (S1P1) and receptor-5 (S1P5) agonist with autoimmune disease-modifying activity. $\mathrm{Br} \mathrm{J}$ Pharmacol. 2016;173:1778-92.

60. Karuppuchamy T, Behrens EH, Gonzalez-Cabrera P, et al. Sphingosine-1-phosphate receptor-1 (S1P1) is expressed by lymphocytes, dendritic cells, and endothelium and modulated during inflammatory bowel disease. Mucosal Immunol. 2017;10:162-71.

61. Sandborn WJ, Feagan BG, Wolf DC, et al. Ozanimod induction and maintenance treatment for ulcerative colitis. N Engl J Med. 2016;374:1754-62.

62. Feagan B, Sandborn W, D'Haens G, et al. P-012 ozanimod, an oral $\mathrm{S} 1 \mathrm{P}$ receptor modulator, is effective and well-tolerated in the long-term treatment of moderate to severe ulcerative colitis. Am J Gastroenterol. 2018;113:S1-S5.

63. Lee J, Mo JH, Katakura $\mathrm{K}$, et al. Maintenance of colonic homeostasis by distinctive apical TLR9 signalling in intestinal epithelial cells. Nat Cell Biol. 2006;8:1327-36. 
64. Atreya R, Bloom S, Scaldaferri F, et al. Clinical effects of a topically applied toll-like receptor 9 agonist in active moderate-to-severe ulcerative colitis. J Crohns Colitis. 2016;10:1294-302.

65. Atreya R, Bloom S, Scaldaferri F, et al. Mo1778 the toll-like-receptor 9 agonist DIMS0150 demonstrates therapeutic efficacy for the patient reported outcome measures PRO-2 and Clinpro in moderate to severe active ulcerative colitis. Gastroenterology. 2016;150(4):S773.

66. Musch E, Lutfi T, von Stein P, et al. Topical treatment with the Toll-like receptor agonist DIMS0150 has potential for lasting relief of symptoms in patients with chronic active ulcerative colitis by restoring glucocorticoid sensitivity. Inflamm Bowel Dis. 2013;19:283-92.

67. Kuznetsov NV, Zargari A, Gielen AW, et al. Biomarkers can predict potential clinical responders to DIMS0150 a toll-like receptor 9 agonist in ulcerative colitis patients. BMC Gastroenterol. 2014;14:79.

68. Ehehalt R, Wagenblast J, Erben G, et al. Phosphatidylcholine and lysophosphatidylcholine in intestinal mucus of ulcerative colitis patients. A quantitative approach by nanoElectrospray-tandem mass spectrometry. Scand J Gastroenterol. 2004;39:737-42.

69. Dial EJ, Zayat M, Lopez-Storey M, et al. Oral phosphatidylcholine preserves the gastrointestinal mucosal barrier during LPS-induced inflammation. Shock. 2008;30:729-33.

70. Karner M, Kocjan A, Stein J, et al. First multicenter study of modified release phosphatidylcholine "LT02" in ulcerative colitis: a randomized, placebocontrolled trial in Mesalazine-refractory courses. Am J Gastroenterol. 2014;109:1041-51.

71. Fertig BA, Baillie GS. PDE4-mediated cAMP signalling. J Cardiovasc Dev Dis. 2018;5(1):8.

72. Papp K, Reich K, Leonardi CL, et al. Apremilast, an oral phosphodiesterase 4 (PDE4) inhibitor, in patients with moderate to severe plaque psoriasis: results of a phase III, randomized, controlled trial (efficacy and safety trial evaluating the effects of apremilast in psoriasis [ESTEEM] 1). J Am Acad Dermatol. 2015;73:37-49.

73. Danese S, Neurath M, Kopon A, et al. OP006 Apremilast for active ulcerative colitis: a phase 2, randomised, double-blind, placebo-controlled induction study. J Crohn's Colitis. 2018;12(supplement 1):S004-S005.

74. Transcribing MF. Celgene (CELG) Q2 2018 earnings conference call transcript. 2018. https:// seekingalpha.com/article/4190643-celgene-celg-q22018-results-earnings-call-transcript. Accessed 25 Jan 2018

75. Paramsothy S, Paramsothy R, Rubin DT, et al. Faecal microbiota transplantation for inflammatory bowel disease: a systematic review and meta-analysis. J Crohns Colitis. 2017;11:1180-99.

76. Rossen NG, Fuentes S, van der Spek MJ, et al. Findings from a randomized controlled trial of fecal transplantation for patients with ulcerative colitis. Gastroenterology. 2015;149(110-118):e4.

77. Moayyedi P, Surette MG, Kim PT, et al. Fecal microbiota transplantation induces remission in patients with active ulcerative colitis in a randomized controlled trial. Gastroenterology. 2015;149(102-109):e6.

78. Paramsothy S, Kamm MA, Kaakoush NO, et al. Multidonor intensive faecal microbiota transplantation for active ulcerative colitis: a randomised placebo-controlled trial. Lancet. 2017;389:1218-28.

79. Costello SP, Waters O, Bryant RV, et al. Short duration, low intensity, pooled fecal microbiota transplantation induces remission in patients with mild-moderately active ulcerative colitis: a randomised controlled trial. Gastroenterology 2017;152;s198-9.

80. Paramsothy S, Cleveland NK, Zmeter N, et al. The role of biosimilars in inflammatory bowel disease. Gastroenterol Hepatol (N Y). 2016;12:741-51.

81. Smits LJ, Derikx LA, de Jong DJ, et al. Clinical outcomes following a switch from Remicade(R) to the biosimilar CT-P13 in inflammatory bowel disease patients: a prospective observational cohort study. J Crohns Colitis. 2016;10:1287-93.

82. Jorgensen KK, Olsen IC, Goll GL, et al. Switching from originator infliximab to biosimilar CT-P13 compared with maintained treatment with originator infliximab (NOR-SWITCH): a 52-week, randomised, double-blind, non-inferiority trial. Lancet. 2017;389:2304-16.

83. Schmitz EMH, Boekema PJ, Straathof JWA, et al. Switching from infliximab innovator to biosimilar in patients with inflammatory bowel disease: a 12-month multicentre observational prospective cohort study. Aliment Pharmacol Ther. 2018;47:356-63.

84. FDA News Release-FDA approves Inflectra, a biosimilar to Remicade. USA food and Drug Administration. 2018. https://www.fda.gov/ newsevents/newsroom/pressannouncements/ ucm494227.htm. Accessed 28 Jan 2018. 
85. FDA News Release-FDA approves Amjevita, abiosimilar to Humira. USA food and Drug Administration. 2018. https://www.fda.gov/ newsevents/newsroom/pressannouncements/ ucm522243.htm. Accessed 29 Jan 2018.

86. Bonovas S, Nikolopoulos GK, Lytras T, et al. Comparative safety of systemic and low-bioavailability steroids in inflammatory bowel disease: systematic review and network meta-analysis. Br J Clin Pharmacol. 2018;84:239-51.

87. Sandborn WJ, Travis S, Moro L, et al. Once-daily budesonide $\mathrm{MMX}(\mathrm{R})$ extended-release tablets induce remission in patients with mild to moderate ulcerative colitis: results from the CORE I study. Gastroenterology. 2012;143(1218-1226):e2.

88. Travis SP, Danese S, Kupcinskas L, et al. Once-daily budesonide MMX in active, mild-to-moderate ulcerative colitis: results from the randomised CORE II study. Gut. 2014;63:433-41.

89. Lichtenstein GR, Travis S, Danese S, et al. Budesonide MMX for the induction of remission of mild to moderate ulcerative colitis: a pooled safety analysis. J Crohns Colitis. 2015;9:738-46.

90. Rubin DT, Sandborn WJ, Bosworth B, et al. Budesonide foam has a favorable safety profile for inducing remission in mild-to-moderate ulcerative proctitis or proctosigmoiditis. Dig Dis Sci. 2015;60:3408-17.

91. Lichtiger S, Present DH, Kornbluth A, et al. Cyclosporine in severe ulcerative colitis refractory to steroid therapy. N Engl J Med. 1994;330:1841-5.

92. Lowry PW, Weaver AL, Tremaine WJ, et al. Combination therapy with oral tacrolimus (FK506) and azathioprine or 6-mercaptopurine for treatmentrefractory Crohn's disease perianal fistulae. Inflamm Bowel Dis. 1999;5:239-45.

93. Christensen B, Gibson P, Micic D, et al. Safety and efficacy of combination treatment with calcineurin inhibitors and vedolizumab in patients with refractory inflammatory bowel disease. Clin Gastroenterol Hepatol. 2018. https://doi.org/10.1016/j. cgh.2018.04.060. 